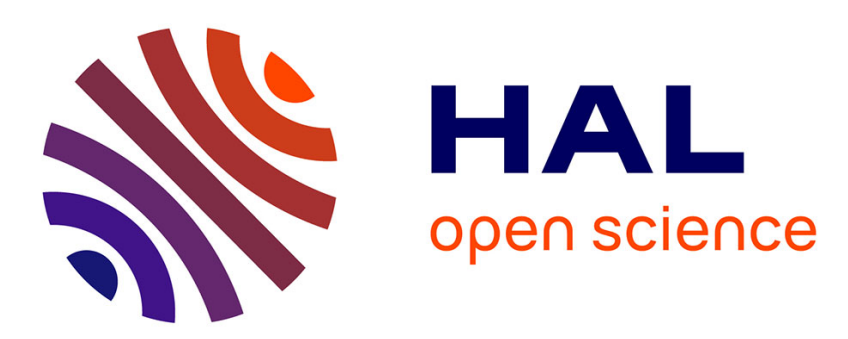

\title{
Tubulin or Not Tubulin: Heading Toward Total Protein Staining as Loading Control in Western Blots
}

\author{
Christian Moritz
}

\section{To cite this version:}

Christian Moritz. Tubulin or Not Tubulin: Heading Toward Total Protein Staining as Loading Control in Western Blots. Proteomics, 2017, 17 (20), 10.1002/pmic.201600189 . hal-01900776

\section{HAL Id: hal-01900776 https://hal.science/hal-01900776}

Submitted on 22 Oct 2018

HAL is a multi-disciplinary open access archive for the deposit and dissemination of scientific research documents, whether they are published or not. The documents may come from teaching and research institutions in France or abroad, or from public or private research centers.
L'archive ouverte pluridisciplinaire HAL, est destinée au dépôt et à la diffusion de documents scientifiques de niveau recherche, publiés ou non, émanant des établissements d'enseignement et de recherche français ou étrangers, des laboratoires publics ou privés. 
This is the pre-peer reviewed version of the following article:

Moritz, C. P. (2017), Tubulin or not tubulin: Heading towards total protein staining as loading control in Western blots. Proteomics, 1600189. Accepted Author Manuscript. doi:10.1002/pmic.201600189

which has been published in final form at

http://onlinelibrary.wiley.com/doi/10.1002/pmic.201600189/ab stract.

If you have access, the final form is recommended as it differs in some parts from the pre-version.

This version of the article may be used for non-commercial purposes in accordance with Wiley Terms and Conditions for Self-Archiving. 
Pre-peer reviewed version of a review article published in PROTEOMICS

\title{
Tubulin or not tubulin: Heading towards total
}

\section{protein staining as loading control in Western}

\section{blots.}

\author{
Christian P. Moritz ${ }^{1,2}$ \\ ${ }^{1}$ Synaptopathies and Autoantibodies, Instutut NeuroMyoGène, Lyon/Saint-Étienne, France \\ ${ }^{2}$ Faculty of Medicine, University Jean Monnet, Saint-Étienne, France
}

Correspondence to:

Dr. Christian P. Moritz

Faculty of Medicine, University Jean Monnet, Saint-Étienne , 10, rue de Marandière, 42270

Saint-Priest-en-Jarez, France

tel.: +33 (0)4 774214 49; fax.: +33 (0)4 774214 38; e-mail: christian.moritz@univ-st-etienne.fr

\section{List of abbreviations:}

HKP: house-keeping protein

TPS: Total protein staining

PVDF: polyvinylidene difluoride

GAPDH: glycerinaldehyd-3-phosphat-dehydrogenase

MS: mass spectrometry

BSA: bovine serum albumin 
5 Keywords: Housekeeping proteins, loading control, total protein staining, Western blot, Immunoblotting

Total number of words: 8,880 


\section{Abstract}

Western blotting is an analytical method widely used for detecting and (semi-)quantifying specific proteins in given samples. Western blots are continuously applied and developed by the protein community. This review article focuses on a significant, but not yet well-established, improvement concerning the internal loading control as a prerequisite to accurately quantifying Western blots. Currently, housekeeping proteins (HKPs) like actin, tubulin, or GAPDH are often used to check for equal loading or to compensate potential loading differences. However, this loading control has multiple drawbacks. Staining of the total protein on the blotting membrane has emerged as a better loading control. Total protein staining (TPS) represents the actual loading amount more accurately than HKPs due to minor technical and biological variation. Further, the broad dynamic range of TPS solves the issue of HKPs that commonly fail to show loading differences above small loading amounts of $0.5-10 \mu \mathrm{g}$. Although these and further significant advantages have been demonstrated over the past ten years, only a small percentage of laboratories take advantage of it. The objective of this review article is to collect and compare information about TPS options and to invite users to reconsider their applied loading control. Nine benefits of TPS are discussed and seven different variants are critically evaluated by comparing technical details. Consequently, this review article offers an orientation in selecting the appropriate staining type. I conclude that TPS should be the preferred loading control in future Western blot approaches. 


\section{Introduction}

Western blotting is a widely-used method to (semi-)quantitatively analyze the abundance of proteins in a given sample [1-3]. Standardly, the proteins of a sample are electrophoretically separated in a polyacrylamide gel according to their mass. In order to immobilize the proteins and to make them accessible for being detected by antibodies, they are transferred from the gel matrix to a membrane (mostly polyvinylidene difluoride [PVDF] or nitrocellulose membranes). This electrophoretic transfer is the actual "blotting" process. On the membrane, a combination of primary and secondary antibodies detects the protein-of-interest. Position and amount can be visualized by chemiluminescent, fluorescent, or other signals [2].

The Western blot technique was invented and published by Harry Towbin and colleagues at the swiss Friedrich Miescher Institute in 1979 [4]. The terms „immunoblotting“ (i.e., immunostaining of membrane-blotted proteins) and "Western blotting" appeared in PubMed-listed publications in 1980 [5] and 1981 [6], respectively.

\subsection{Out-of-date method Western blotting? Not at all!}

Since targeted mass spectrometry was considered to replace Western blots [7], one might ask if it is still appropriate to publish a review article about improving Western blots. To address this concern, I assessed the popularity of this technique by the number of publications mentioning it (Fig. 1). My screening included the terms "immunoblot" ${ }^{\star 1}$ or "Western blot" and covered all Text Words ${ }^{2}$. For the sake of simplicity, "Western blot" will be used as an umbrella term in this review article to cover all of the variants. Starting from the first publications in the early 1980 s, the PubMed entries for Western blot increased in a largely continuous way, reaching about 21,000 publications per year in 2015 (Fig. 1A). Of course, increasing publication numbers are not necessarily a sign of increasing success, as the total numbers of protein-related publications

\footnotetext{
${ }^{1}$ comprising "immunoblots", "immunoblotting”, etc.; all Pubmed searches were performed on April 14, 2017

${ }^{2}$ comprising title, abstract, MeSH headings and subheadings, and other term fields, such as keywords; final search term: Western blot*[Text Word] OR Immunoblot*[Text Word]
} 
likewise increased continuously and reached about 206,000 in $2015^{3}$ (Fig. 1B). Thus, a better way to rate its evolution is to normalize the number of protein-related publications applying Western blots ${ }^{4}$ with the number of all protein-related publications ${ }^{3}$. Notably, the percentage of protein-related publications using the Western blot technique mounted to about $8-9 \%$ within the first 10 years and remained at this high value until today (Fig. 1C). In contrast, the percentage of protein-related publications using mass spectrometry (MS) ${ }^{5}$ among the same set publications reached its maximum of $4 \%$ in 2010 and remained at a level between 3.5 and $4 \%$ since that (Fig. 1D). Thus, despite the appearance of other (semi-)quantitative detection methods, there are no indices of a replacement so far. Western blotting kept its significance in protein-related science during the last 25 years. Reasons for its consistent success might be the lower costs in comparison to MS and the ongoing quality improvements of the Western blotting technique regarding transparency of antibody usage, unspecific staining, efficacy, sensitivity, dynamic range, and reproducibility $[1,3,8-13]$. Independent of the reasons, these data demonstrate that Western blots are not out-of-date and that it is indeed still appropriate to improve the technique and to report about it.

This review article focusses improvements concerning the internal loading control as a prerequisite of exact (semi-)quantitative analysis. Significant progress has emerged in this field within the recent 10 years, but only a small percentage of laboratories are aware of it and profit from it. To change this is the objective of my review article.

\subsection{House-keeping protein as loading control - where is the problem?}

In most cases, a comparative Western blot approach relies on an equal amount of protein load in each lane. Thus, a protein determination (e.g., a bicinchoninic acid assay) is usually

\footnotetext{
3 search term: protein*[Text Word] OR proteom*[Text Word]

${ }^{4}$ (protein*[Text Word] OR proteom*[Text Word]) AND (Western blot*[Text Word] OR Immunoblot*[Text Word])

${ }^{5}$ (protein*[Text Word] OR proteom*[Text Word]) AND ("mass spectrometry"[Text Word] OR "mass spectrometric"[Text Word])
} 
performed before protein loading. Since multiple steps lie between the protein determination and the visualization of blotted proteins, several factors can prevent that proteins are equally loaded at the membrane level. These factors can be (1) erroneous protein determination, e.g., due to incompatible compounds in the lysis buffer, (2) inhomogeneous protein loading into the lanes, e.g., due to bubbles in the pipette tip, (3) inhomogeneous protein separation in the acrylamide gel, e.g. due to inconsistent protein entry into the gel matrix, and (4) unequally efficient protein transfer. To control equal loading or to compensate potential loading differences at the level of transferred proteins, many laboratories standardly perform immunostainings of HKPs like actin, tubulin, or glycerinaldehyd-3-phosphat-dehydrogenase (GAPDH; recent examples in this journal: [14-18]). The use of these proteins is based on the assumption that they are equally expressed in any tissue or condition. During the recent two decades, the protein community has become aware that this assumption is wrong. Examples of unequally expressed HKP have been manifold reported and will not be comprehensively reviewed in this publication. As a brief summary, I want to point to only two important publications of the journal PROTEOMICS that have been more than 150-fold cited. As the first example, a survey article has presented the top 15 most often identified differentially expressed proteins in proteomics studies. GAPDH was one of these déjà vu proteins appearing in $12 \%$ of the differential experiments [19]. A second study has tested the degree of variability of the three commonly used HKPs GAPDH, $\beta$-actin, and $\beta$ tubulin in different conditions (disease states and tissue types) and found significant variation in at least one condition [20]. As HKPs participate in many and fundamental intracellular processes, it is not surprising that many aspects affect the expression of these proteins. Thus, the authors of both publications suggested to reconsider the HKP's role as an internal standard in both proteomics and transcriptomics experiments.

Another problem of using HKPs can result from their high abundance. As loading amounts are usually optimized for the protein of interest, abundant HKPs may be overloaded. As a result, immunosignals of HKPs may often be oversaturated and thus not able to detect differences. For 
example, evidence suggests that actin, GAPDH, and tubulin are saturated in most of the publications where they are used as a loading controls, as they are unable to show any loading differences above relatively small total protein loading amounts of about $0.5-10 \mu \mathrm{g}$. In detail, immunosignals of actin saturate above total protein loading amounts of $2 \mu \mathrm{g}$ of $\mathrm{HzAm} 1$ cell lysate (PVDF, chemiluminescence) [21], $0.5 \mu \mathrm{g}$ (monoclonal) or $2 \mu \mathrm{g}$ (polyclonal) of MDA-MB231 breast cancer cell lysate (PVDF, chemiluminescence) [22], or $10 \mu \mathrm{g}$ of subcellular fractions of mouse cortex (nitrocellulose, chemiluminescence) [23] (but: $30 \mu \mathrm{g}$ of rat hippocampal lysate (PVDF, chemiluminescence) [24]. Similarly, immunosignals of GAPDH saturate above total protein amounts of $4 \mu \mathrm{g}$ of HeLa cell lysate (PVDF, film) [25], $5 \mu \mathrm{g}$ of LU-HNSCC-4 cell lysate (PVDF, chemiluminescence) [26], 5-10 $\mu \mathrm{g}$ of hippocampal lysate (PVDF, chemiluminescence) [24], or $10 \mu \mathrm{g}$ of nuclear and cytoplasmic fractions from mouse cortex (nitrocellulose, chemiluminescence) [23]. Likewise, $\alpha$-tubulin and $\beta$-tubulin saturate above loading ranges of about $4 \mu \mathrm{g}$ and $10 \mu \mathrm{g}$ total protein of mouse ovary lysate and whole brain lysate (PVDF, chemiluminescence and fluorescence), respectively $[27,28]$.

As a last issue, even an equally expressed and not oversaturated HKP can be excluded by another limiting factor: If its molecular weight lies in the same range as that of the protein-ofinterest, disturbing effects are probable even if the primary antibodies against the two proteins have different hosts.

Nevertheless, the consequences of understanding these issues develop slowly: many laboratories still use HKPs as loading controls. The reason may be that researchers lack knowledge of accepted alternatives and/or their advantages.

\section{Alternatives for the classical loading control}

The following alternatives have been suggested to solve the above mentioned problems: 
- Averaging more than one HKP as a loading control in order to make errors due to the above mentioned issues less probable [29] (similar to quantitative RNA analysis [30]). Accompanying problem: the experimental time and costs are additionally extended and the above mentioned saturation issue is not solved.

- Thoroughly searching and characterizing the appropriate HKPs before each project $[29,31-33]$.

Accompanying problem: time-consuming work.

- Spiking-in equal amounts of a standard into each sample (similar to quantitative RNA analysis [34,35]).

Accompanying problem: spike-in protein(s) must be chosen, acquired, and tested, which is time-consuming.

- Visualizing the total protein of the gel before transfer [36].

Accompanying problem: this method misses controlling the transfer as one common source of variance.

- Visualizing the total protein of a parallel gel [28].

Accompanying problem: same as for the previous point.

- Visualizing the transferred total protein on the membrane

During the recent years, the latter alternative has emerged as the most convenient. The next part of my review article will elucidate the rationale and the advantages of total protein staining (TPS) and compare the properties of the different variants of this new loading control.

\subsection{The rationale of using total protein staining}

The aim of any loading control is to get an idea of each lane's total protein amount that has been transferred to the blotting membrane. In the classical loading control, the amount of the chosen HKP should represent this total protein amount. Already a simple theoretic consideration may 
convince: In order to get a measure for the total protein amount, what would be more obvious than staining the total protein?

The next chapters summarize the general advantages of TPS as laoding controls and introduce six tested and recommended staining types.

\subsection{Advantages of total protein staining}

Using TPS as loading control has nine advantages over the usage of HKPs:

\section{- Smaller technical variation}

Evidence suggests that the technical variation of the quantified total protein signal - e.g., variation between different lanes or membranes - is significantly smaller than that of HKPs. In detail, the average lane-to-lane-variation of proteins from homogenized rat brain tissue was $9.9 \%$ for a fluorescence-based TPS (Epicocconone) versus $31.3 \%$ and $12.9 \%$ for immunostaining of GAPDH and $\beta$-tubulin, respectively [37]. Another study performed a proof-of-principle experiment: different loading controls were used to arithmetically compensate manually set loading differences [24]. With a TPS based on Ponceau S, the detected protein ratios technically varied by a relative coefficient of variance $(\mathrm{CV} \%)$ of $9 \%$. With actin as loading control, the result showed a high technical variation of $58 \%$.

\section{- Smaller biological variation}

Biological variation of the total protein signal - e.g., variation between individual animals, organs, or diseases - is significantly smaller than the immunosignal of HKPs. In detail, the CV\% among established cell lines was $7.2 \%$ for a Coomassie-based TPS versus $28.0 \%$ for immunostaining of $\beta$-actin [20]. The same authors measured $6.9 \%$ variation for Coomassie-based TPS when comparing disease states of renal tissue, in contrast to 
$18.7 \%$ for $\beta$-actin and $41.1 \%$ for GAPDH. Further, the average variation of Epicocconone-based TPS was $13.1 \%$ among different brain regions, while immunosignals of $\beta$-tubulin and GAPDH varied four to six times stronger $(51.7 \%$ and 80.3\% respectively [37]). Even if the variation of HKP abundance might be milder when comparing more similar samples, it appears logical that the total protein varies less than a selected single protein.

\section{- Unlikely signal saturation}

There is no evidence of signal saturation for TPS when loading common protein amounts per lane (i.e., dynamic range maxima of $30 \mu \mathrm{g}$ to $140 \mu \mathrm{g}$ protein; Table 1). This is in strong contrast to immunosignals of HKPs (see above). Only Ponceau S may saturate at high amounts of around $120 \mu \mathrm{g} / \mathrm{lane}$ [38], while the upper dynamic range limit has not been described for other stainings.

\section{- No collision between immunosignal and loading control}

TPS visualizes proteins by mechanisms that are different from immunostaining. Thus, the signal of the protein of interest and that of the loading control do not collide.

Nevertheless, TPS might be incompatible with subsequent immunostaining. However, no adverse effects of TPS on subsequent techniques have been reported for most of the recommended stainings (Table 1 ).

\section{- Cheaper than immunostaining}

The prize for TPS ranges between $<1.40 € /$ blot membrane for Coomassie, Amido Black, as well as Ponceau $S$ staining and $<3 € /$ blot membrane for stain-free, epicocconone, and SyproRuby staining. This is 7 to $>20$ times cheaper than the corresponding prize for immunostaining of a HKP using commercial antibodies (Supplementary Table 1). 


\section{- Faster than immunostaining}

The six TPSs tested so far last $\leq 30$ minutes including destaining (where appropriate, Table 1). This is significantly shorter than the duration of standard immunostaining processes (>2h), unless (1) one simultaneously incubates the antibody-of-interest and the antibody against the HKP or (2) one uses fast Western blot systems.

\section{- Early quality control of the protein transfer}

The TPS on the membrane offers visualizing the band and lane pattern of the transferred proteins prior to further analyses. In case of an inhomogeneous transfer affecting the mass region of interest, this allows to discard the membrane in an early state, which saves time and money.

\section{- Efficient handling of inhomogeneous transfers}

In case of an inhomogeneous transfer not affecting the mass region of interest, a subpart of the lane, e.g., 70-100 kDa consistently for all lanes, is sufficient for adequate normalization [39]. This is not possible with immunosignals of HKP.

\section{- Match the band-of-interest with a complex band pattern}

The immunosignal of the protein-of-interest can be matched with the total protein signal, which allows to allocate a band/spot of interest in a complex pattern [40]. 


\section{Proposed TPSs and their properties}

To my knowledge, six different TPS have been tested and published as options for loading controls (Table 1). These are based on Ponceau S [41], stain-free techniques [42], SyproRuby [23], Epicocconone [37], Coomassie R-350 [26], and Amido Black [39].

While plenty of data are available about total protein stainings on the level of acrylamide gels (main focus of [43]), much less is known on the level of blotting membranes. However, it is relevant to distinguish between gel-based and membrane-based data, as staining efficacy may differ and protein can be lost during the blotting process. In numbers, detecting proteins on blotting membranes can be up to around 10-fold less sensitive (assessed with loading values prior to gel electrophoresis $[44,45]$ versus $[37,46]$; $[47]$; $[44,48]$ versus $[37,49])$. Therefore, as equal loading is controlled optimally after protein transfer, I have only surveyed data obtained at the level of blotting membranes (both PVDF and nitrocellulose) for this review article. To summarize relevant data comprehensively, I surveyed information that researchers usually take into account when choosing an appropriate loading control (Table 1). These data comprise dynamic range and its regression model (linear or logarithmic), detection limit, technical variation, visualization devise, compatibility with subsequent analytical techniques, staining duration, and environmental/health aspects. For the dynamic range and the detection limit, Table 1 further indicates the respective membrane type and protein source of each reference, as these conditions may influence the performance. Alike, the sample size is indicated for the technical variation.

The dynamic range limited the usability of many HKPs as classical loading controls (see above). Therefore, Figure 2 highlights this property and visualizes the dynamic ranges of the suggested

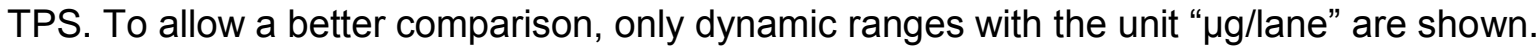
In the next subchapters, I summarize the properties of the individual TPS approaches. 


\subsection{Ponceau S}

Ponceau $S$ is a negatively charged sodium salt of a diazo dye and binds to positively charged amino acids as well as non-polar regions of proteins. No special devices are needed to visualize the staining $[50,51]$.

Klein et al. to my knowledge were the first who described the need of internal loading control in 1995 [41]. They used Ponceau S staining as their alternative to HKPs (Table 1). Nevertheless, HKPs prevailed as the standard loading control. During the last 10 years, TPS experienced a new rise as loading controls and Ponceau $\mathrm{S}$ has been suggested for a second time [52]. In this latter study, Ponceau $S$ has a similar linear dynamic range (10-140 $\mu \mathrm{g} / \mathrm{lane})$ as the exemplarily chosen actin. Also other publications found a linear $\left(R^{2}=0.92-0.99\right)$ dynamic range from $\leq 10$ or $\leq 5 \mu \mathrm{g} /$ lane up to $\geq 45, \geq 50$, or up to maximally $120 \mu \mathrm{g} /$ lane (Table 1 ) and confirmed Ponceau as a better loading control than ( $\beta$-)actin, $\alpha$-tubulin, GAPDH, or TPS with Coomassie $[24,39,53]$. Nevertheless, its calibration curve is less steep than for example fluorescence-based TPS [53], making it less sensitive towards small loading differences as they may commonly occur in Western blots. In a proof-of-principle experiment, different stainings were used to arithmetically control manually set loading differences [24]. With Ponceau S as loading control, the analyzed protein ratios were $42 \%$ above the theoretically expected value, while the variation was very low (CV\%: 9\%). With actin as loading control, the obtained protein ratios were $34 \%$ below the theoretically expected value, but showed a very high variation (58\%), why the authors conclude that Ponceau S has a better performance than actin. In total, Ponceau may be a better loading control than using HKPs, but is still not optimal.

Ponceau S staining on blotting membranes is relatively fast (5-20 min), reversible, and not adversely affecting subsequent analytical techniques [50]. 


\subsection{Stain-free technique}

The stain-free technique is based on trihalo-compounds, such as Trichloroethanol, that are incorporated into polyacrylamide gels. The staining compound covalently binds tryptophan residues of proteins under UV exposure [54]. Due to covalent binding of the trihalo-compound, proteins are detectable not only on gels, but also on membranes after protein transfer $[42,53,55]$. The resulting fluorescence emission must be detected with a fluorescence imager. This technique was presented as a loading control of Western blots by Colella and colleagues in 2012 [42] (Table 1). Its linear $\left(R^{2}=0.98-0.99\right)$ dynamic range comprises loading amounts of $\leq 10$ to $\geq 50 \mu \mathrm{g} / \mathrm{lane}$ [53] or even $\leq 5$ to $\geq 120 \mu \mathrm{g} / \mathrm{lane}$ [38] and supports its superiority to the use of HKP. Further it is less variable than immunostaining of actin (CV\%: $9.7 \pm 2.3 \%$ vs. $13.0 \pm 2.9 \%$ [38]) and its dilution curve is steeper [53] than that of Ponceau S staining, which is advantageous in detecting loading differences.

A disadvantage becomes evident when working in low protein loading ranges. Due to its reported detection limit, the stain-free method may not work when loading less than 3-5 $\mu \mathrm{g}$ of total protein per lane [25].

A second disadvantage is its staining mechanism. As it detects tryptophan residues, proteins lacking tryptophan are invisible, which may lead to a staining bias.

A third but minor disadvantage may be the insufficient data concerning its dynamic range, making it difficult to assess the regression model of its calibration curve. So far, the tested dilution series spanned only 1-2 orders of magnitude (10-50 $\mu \mathrm{g} / \mathrm{lane}$ [53], 10-40 $\mu \mathrm{g} / \mathrm{lane}$ [42], 5$60 \mathrm{ng} / \mathrm{lane}$ [55], 5-120 $\mu \mathrm{g} / \mathrm{lane}$ [38]) and are thus not broad enough to make a clear conclusion about the regression model. In three of these publications the demonstrated points of the calibration curve might fit to both linear and logarithmic regression models. There is no evidence that the stain-free approach adversely affects subsequent MS and immunostaining (Table 1). However, no systematic test addressing MS of tryptophan-containing 
peptides or immunostaining with antibodies raised against a peptide region that contains tryptophan has been performed to my knowledge.

\subsection{Sypro Ruby}

Sypro Ruby is a permanent stain that interacts non-covalently with proteins based on an organic compound comprising ruthenium [46]. Sypro Ruby was shown to be more accurate in reflecting the differences in protein concentration and thus suggested as an appropriate loading control for Western blots. (Table 1, [23]). To visualize the fluorescence emission, a fluorescence imager is necessary.

The dynamic range has been shown to run from $\leq 10$ to $\geq 40 \mu \mathrm{g} /$ lane or from $\geq 1 \mu \mathrm{g}$ (about the detection limit) up to $\geq 30 \mu \mathrm{g} /$ lane (Table 1). As the published data are inconsistent in whether its staining behavior is linear or logarithmic, it is recommended to test it with appropriate dilution series and devises in each laboratory prior to analysis.

Sypro Ruby staining is relatively fast (20 min), but as a disadvantage, it may not be completely compatible with subsequent mass spectrometry. In detail, prior staining can inhibit the identification of cysteine and tryptophan containing peptides for peptide mass fingerprinting using MALDI-MS [56].

\subsection{Epicocconone}

Epicocconone is a fluorescent polyketide naturally occurring in the fungus Epicoccum nigrum and it interacts non-covalently with sodium dodecyl sulfate and proteins [48,49]. Epicocconone is also available as a synthetic compound [57]. Epicocconone-based stainings are also referred to as Deep Purple, Lava Purple, or SERVA Purple. To visualize the fluorescence emission, a fluorescence imager is necessary. Epicocconone-based TPS was recommended as a superior loading control in 2014 [37] and successfully applied thereafter [58]. Its dynamic range extends from $0.1 \mu \mathrm{g}$ (about the detection 
limit) to at least $30 \mu \mathrm{g} /$ lane (Table 1). However, as for Sypro Ruby, it is not completely clear which regression model the calibration curve follows. I see stronger evidence for a logarithmic regression model [37], as the reports of a linear model (in gel staining, however) are based on non-linearly transformed data $[44,48]$.

Except of one study [37], Epicocconone-based staining was characterized only on gel level, not on blotting membranes. Nevertheless, the advantages over other total protein stainings, such as the higher sensitivity and broader dynamic range, were also detected on gels [48].

Epicocconone staining is relatively fast (30 $\mathrm{min})$ and does not adversely affect subsequent MS and immunostaining (Table 1).

\subsection{Coomassie}

Coomassie forms strong but non-covalent, primarily electrostatically interacting complexes predominantly with proteins containing the basic amino acids arginine and lysine $[59,60]$. No special devices are needed to visualize the staining.

Commassie staining of the membrane after immunostaining was suggested as an appropriate loading control [26]. Its dynamic range is linear $\left(R^{2}=0.96\right)$ and extends from $1 \mu \mathrm{g}$ (about the detection limit) to at least $30 \mu \mathrm{g} /$ lane (Table 1). Staining is relatively fast (21 $\mathrm{min}$ ) and does not adversely affect subsequent MS (Table 1). Incompatibility with subsequent immunostaining has often been stated as a drawback of this method, but I did not find any publication giving evidence for this statement. In contrast, there is evidence for compatibility [61-64]. However, as for most of the other stainings, the impact on immunostaining has not been systematically tested to my knowledge.

It should be noted that the use of Coomassie as a near-infrared fluorescent stain may be equivalent to classical fluorescent stainings $[28,64,65]$. This advancement could render Commassie staining to a promising loading control. However, similar to the other fluorescence 
stainings, Coomassie near-infrared tends to follow an rather nonlinear regression when regarding a broad loading range (only data on gel level available [64]).

\subsection{Amido Black}

Amido Black non-covalently binds predominantly basic amino acids primarily via electrostatic interaction [66]. No special devices are needed to visualize the staining.

Amido Black was shown to be more accurate in reflecting the differences in protein concentration than immunosignals of actin and GAPDH [23]. Another study confirmed that it is a better loading control than $\alpha$-tubulin, $\beta$-actin, and GAPDH [39]. Its dynamic range is probably linear $\left(R^{2}=0.75\right)$ and measures at least between $22-41 \mu \mathrm{g} / \mathrm{lane}$ (Table 1). However, it is less sensitive than fluorescence-based TPS. For example, the detection limit of Sypro Ruby is $0.25-1$ $\mathrm{ng} / \mathrm{mm}^{2}$ [46], while that of Amido Black is 4-8 $\mathrm{ng} / \mathrm{mm}^{2}$ [67], hence 4-32 times lower. As another disadvantage, the CV\% is 30\% [23] and thus higher than that of other TPSs (Table 1). Amido Black staining is relatively fast (30 min) and does not adversely affect subsequent immunostaining (Table 1; not systematically tested).

\section{And the winner is... relative}

After summarizing the details of the staining properties of six proposed TPSs loading controls, I dare to offer the global conclusion that TPSs should be preferred to immunostainings of HKPs. Even if one has proven that the chosen HKP does not face the saturation and variability problems that are common in other labs, benefits of TPS in time and cost may convince. However, the question remains which staining technique should be preferred? Recommending one specific technique would be too simple, as disregarding the pros and cons of each technique.

To find the appropriate TPS, each laboratory has to rate the staining properties according to the needs. For example, if a lab lacks a fluorescence detecting device, fluorescence-independent 
techniques should be applied, such as Ponceau S, Commassie, or Amido Black staining. If very high protein amounts are loaded (i.e., around $100 \mu \mathrm{g} / \mathrm{lane}$ ), the stain-free approach may be suitable, while Ponceau S may have reached its saturation limit; other stainings have not been tested with these high amounts (Table 1 and Figure 1). If very low protein amounts are loaded (i.e., $1-5 \mu \mathrm{g} / \mathrm{lane}$ ), Sypro Ruby, Epicocconone, or Commassie may be the suitable technique as their dynamic range expands down to $1 \mu \mathrm{g}$. Epicocconone staining should be applied for even lower loading amounts as it is the only technique with a dynamic range comprising values $<1 \mu \mathrm{g}$ (Table 1 and Figure 1). Some authors suggest the use of GAPDH [25,31] or beta-actin [21] as a loading control in such cases, since these HKPs are not saturated in minimal loading ranges. However, the other mentioned drawbacks of HKP - as its unequal expression and its high variation - may remain also with low protein loading. This is an unnecessary risk, especially since samples loaded in minor amounts are often precious. Thus, I suggest to adhere to sensitive total protein stainings, such as Epicocconone-based staining, which works in low loading ranges between $0.1 \mu \mathrm{g}$ and $3 \mu \mathrm{g}$ [37].

If time is the limiting factor, the stain-free technique is preferable as the staining compound is already present in the polyacrylamide gel. Hence, the staining steps can be skipped.

\section{Improvements of the HKP method}

Gürtler and colleagues compared the stain-free TPS approach with immunofluorescence (instead of chemiluminescence) staining of GAPDH [55]. The calibration curve of the HKP was reliably linear $\left(R^{2}=0.99\right)$, such as that of the stain-free approach $\left(R^{2}=0.98\right)$, and both stainings extended from at least 5-60 $\mu \mathrm{g}$ protein per lane. Similarly, Weldon and colleagues found that changing the detection method from chemiluminescence to near-infrared fluorescence improved the suitability of HKP as loading controls [68]. Immunofluorescence staining is also more sensitive than chemiluminescence staining [69]. This may lead to the assumption that the problem in using HKPs derives from applying a chemiluminescence approach [32], not from the 
character of HKPs in general. Nevertheless, normalization with the stain-free TPS approach, but not with HKP immunofluorescence, allowed detecting and compensating small loading differences [55]. Further, Eaton et al. have displayed the variability of HKPs among tissue types and disease states even with immunofluorescence [28]. These results demonstrate that the superiority of TPS as loading control persists even when using the more reliable and more sensitive immunofluorescence staining of HKP. However, when insisting on HKP as loading control, near-infrared fluorescence-based immunostainings should be considered.

\section{Other potential stainings}

Further TPS, albeit not yet recommended as loading controls for Western blots, can be considered as alternatives to immunostainings and to the other mentioned TPSs. The details of a selection of these staining types are listed in Table 2 . The most potential one regarding sensitivity and dynamic range may be Coomassie staining with a near-infrared detection [64] or staining with Ferrozine-ferrous complexes or Pyrogallol red-molybdate complexes [70]. Apart from the stainings listed in Table 2, several other membrane stainings have been published and may be tested as loading control [71]. Further TPS are continuously improved and invented, but some may fail as membrane stains. For example, a rapid staining method via Dichlorofluorescein was recently reported to be more sensitive than silver staining and Sypro Ruby [72], but as it reacts with the gel matrix (negative staining), it may not be applicable to stain membranes. By using glycoprotein-selective stainings, one could consider normalizing the protein-of-interest with the total set of glycoproteins [73].

The Smart Protein Layers (SPL) technology has been developed as a sophisticated extension of the fluorescence-based TPS to control further eventualities [74]. Faden et al. describe the use of manually added internal loading controls in addition to the TPS. In detail, they added a fluorescent internal standard protein to every reaction in order to control the efficiency and homogeneity of the TPS. Another standard protein is added to control the binding efficiency of 
the secondary antibody. The superiority of this method over others has not been systematically tested so far.

\section{Limitations of the data - implications for future studies}

In the cited publications, protein amounts refer to five different dimensions: lane, band, dot, slot, and $\mathrm{mm}^{2}$. Varying the dimensions can limit the comparability of the staining properties. As an example, a staining technique may detect $10 \mathrm{ng}$ of a purified protein (e.g., BSA) as a single band. In contrast, the same protein amount of a complex cell lysate may be below the detection limit, as any of the multiple protein bands contains much less than $10 \mathrm{ng}$ proteins. To deliver transparent data, Tables 1 and 2 indicate the appropriate dimension of the given protein amounts. I suggest that future publications do is likewise when referring to properties such as detection limits or dynamic ranges. Indicating protein amounts in grams per $\mathrm{mm}^{2}$ might be the most constructive way, as the alternatives (lane, band, dot, slot) can differ in size and are hence not always conclusive.

Further, variable ways of how proteins are applied to the membrane can limit the comparability of staining techniques. For example, dot or slot blotting circumvents protein loss during transfer and may thus provide better values for staining sensitivity than electroblotting does. To get a real idea of sensitivity and linear dynamic range of the staining techniques in absolute numbers, it makes sense to perform direct slot or dot blots. Nevertheless, transfer blotting allows a relative comparison, albeit the absolute numbers may be biased.

As a further limitation affecting most of the data published about the staining properties, the tested dilution series do not cover the stainings' full dynamic range. Future studies should expand the series to detect the detection and saturation limits, or the amounts where the regression model of the curve changes. 
Finally, compatibility with subsequent techniques has been attested for any of the recommended staining types (Table 1). However, although the presence of immunosignals on prestained membranes may argues for compatibility, TPS might still disturb subsequent immunostaining. To describe the compatibility in a more detailed way, more systematical tests are necessary. These should include more than one protein, statistically valid comparison of signal intensities on prestained versus unstained membranes, and a potential impact on the calibration curve. So far, this has been performed only for Epicocconone staining [37].

\section{Conclusion}

Due to the multiple advantages of TPS as loading control for Western blots, I am convinced that normalization standards will change during the next years. To my knowledge, the Journal of Biological Chemistry was in 2015 the first one that cautions their authors against the use of housekeeping proteins for normalization and encourages to use TPS instead [75]. Here, I summarized rationale and reasoning and finally conclude that TPS should be preferred to immunostaning of HKPs. Further, I have addressed different types of TPS on blotting membranes in order to facilitate the decision about which technique to choose as loading control for Western blots.

\section{Acknowledgements}

I thank Thomas Schulenborg for the Shakespearian idea for the title and Dennis Diefenbach for his help with the reference managing software. 


\section{Funding sources}

Christian Moritz is funded by a research fellowship of the Deutsche Forschungsgemeinschaft (DFG).

\section{Conflict of interest}

The author has declared no conflict of interest.

\section{References}

[1] Eaton, S.L., Hurtado, M.L., Oldknow, K.J., Graham, L.C., et al., A Guide to Modern Quantitative Fluorescent Western Blotting with Troubleshooting Strategies. J. Vis. Exp. 2014, e52099.

[2] Ni, D., Xu, P., Gallagher, S., in:, Curr. Protoc. Protein Sci., vol. 88, John Wiley \& Sons, Inc., Hoboken, NJ, USA 2017, p. 10.10.1-10.10.37.

[3] Taylor, S.C., Posch, A., The Design of a Quantitative Western Blot Experiment. Biomed Res. Int. 2014, 2014, 1-8.

[4] Towbin, H., Staehelin, T., Gordon, J., Electrophoretic transfer of proteins from polyacrylamide gels to nitrocellulose sheets: procedure and some applications. Proc. Natl. Acad. Sci. U. S. A. 1979, 76, 4350-4.

[5] Matus, A., Pehling, G., Ackermann, M., Maeder, J., Brain postsynaptic densities: the relationship to glial and neuronal filaments. J. Cell Biol. 1980, 87, 346-59.

[6] Burnette, W.N., \&quot;Western blotting\&quot;: electrophoretic transfer of proteins from sodium dodecyl sulfate--polyacrylamide gels to unmodified nitrocellulose and radiographic detection with antibody and radioiodinated protein A. Anal. Biochem. 1981, 112, 195-203.

[7] Picotti, P., Bodenmiller, B., Aebersold, R., Proteomics meets the scientific method. Nat. Methods 2013, 10, 24-7. 
[8] Sasaki, A., Arawaka, S., Sato, H., Kato, T., Sensitive western blotting for detection of endogenous Ser129-phosphorylated a-synuclein in intracellular and extracellular spaces. Sci. Rep. 2015, 5, 14211.

[9] Gilda, J.E., Ghosh, R., Cheah, J.X., West, T.M., et al., Western Blotting Inaccuracies with Unverified Antibodies: Need for a Western Blotting Minimal Reporting Standard (WBMRS). PLoS One 2015, 10, e0135392.

[10] Matsugu, H., Nishikata, T., Improved antigen detection on western blots. Tech. Tips Online 2001, 6, 34-36.

[11] Kiyatkin, A., Aksamitiene, E., Multistrip western blotting to increase quantitative data output. Methods Mol. Biol. 2009, 536, 149-61.

[12] Wu, M., Stockley, P.G., Martin, W.J., An improved western blotting technique effectively reduces background. Electrophoresis 2002, 23, 2373-6.

[13] Bandrowski, A.E., Martone, M.E., RRIDs: A Simple Step toward Improving Reproducibility through Rigor and Transparency of Experimental Methods. Neuron 2016, 90, 434-6.

[14] Tran, T.T., Strozynski, M., Thiede, B., Quantitative phosphoproteome analysis of cisplatininduced apoptosis in Jurkat T cells. Proteomics 2017, 1600470.

[15] Dyshlovoy, S.A., Otte, K., Venz, S., Hauschild, J., et al., Proteomic-based investigations on the mode of action of the marine anticancer compound rhizochalinin. Proteomics 2017, 1700048.

[16] Rahn, J., Lennicke, C., Kipp, A.P., Müller, A.S., et al., Altered protein expression pattern in colon tissue of mice upon supplementation with distinct selenium compounds. Proteomics 2017, 1600486.

[17] Höti, N., Shah, P., Hu, Y., Yang, S., Zhang, H., Proteomics analyses of prostate cancer cells reveal cellular pathways associated with androgen resistance. Proteomics 2017, 17, 1600228.

[18] Mir, S.A., Pinto, S.M., Paul, S., Raja, R., et al., SILAC-based quantitative proteomic 
analysis reveals widespread molecular alterations in human skin keratinocytes upon chronic arsenic exposure. Proteomics 2017, 17, 1600257.

[19] Petrak, J., Ivanek, R., Toman, O., Cmejla, R., et al., Déjà vu in proteomics. A hit parade of repeatedly identified differentially expressed proteins. Proteomics 2008, 8, 1744-9.

[20] Ferguson, R.E., Carroll, H.P., Harris, A., Maher, E.R., et al., Housekeeping proteins: a preliminary study illustrating some limitations as useful references in protein expression studies. Proteomics 2005, 5, 566-71.

[21] Chen, W., Xu, W.-H., $\beta$-Actin as a loading control: Less than $2 \mu \mathrm{g}$ of total protein should be loaded. Electrophoresis 2015, 36, 2046-9.

[22] Dittmer, A., Dittmer, J., $\beta$-Actin is not a reliable loading control in Western blot analysis. Electrophoresis 2006, 27, 2844-2845.

[23] Aldridge, G.M., Podrebarac, D.M., Greenough, W.T., Weiler, I.J., The use of total protein stains as loading controls: an alternative to high-abundance single-protein controls in semi-quantitative immunoblotting. J. Neurosci. Methods 2008, 172, 250-4.

[24] Thacker, J.S., Yeung, D.H., Staines, W.R., Mielke, J.G., Total protein or high-abundance protein: Which offers the best loading control for Western blotting? Anal. Biochem. 2016, 496, 76-8.

[25] Taylor, S.C., Berkelman, T., Yadav, G., Hammond, M., A defined methodology for reliable quantification of Western blot data. Mol. Biotechnol. 2013, 55, 217-26.

[26] Welinder, C., Ekblad, L., Coomassie Staining as Loading Control in Western Blot Analysis. J. Proteome Res. 2011, 10, 1416-1419.

[27] Suzuki, O., Koura, M., Noguchi, Y., Uchio-Yamada, K., Matsuda, J., Use of sample mixtures for standard curve creation in quantitative western blots. Exp. Anim. 2011, 60, 193-6.

[28] Eaton, S.L., Roche, S.L., Llavero Hurtado, M., Oldknow, K.J., et al., Total protein analysis as a reliable loading control for quantitative fluorescent Western blotting. PLoS One 2013, 
8, e72457.

[29] Prokopec, S.D., Watson, J.D., Pohjanvirta, R., Boutros, P.C., Pohjanvirta, R., Identification of Reference Proteins for Western Blot Analyses in Mouse Model Systems of 2,3,7,8-Tetrachlorodibenzo-P-Dioxin (TCDD) Toxicity. PLoS One 2014, 9, e110730.

[30] Vandesompele, J., De Preter, K., Pattyn, F., Poppe, B., et al., Accurate normalization of real-time quantitative RT-PCR data by geometric averaging of multiple internal control genes. Genome Biol. 2002, 3, RESEARCH0034.

[31] Yu, H.-R., Kuo, H.-C., Huang, H.-C., Huang, L.-T., et al., Glyceraldehyde-3-phosphate dehydrogenase is a reliable internal control in Western blot analysis of leukocyte subpopulations from children. Anal. Biochem. 2011, 413, 24-9.

[32] Charette, S.J., Lambert, H., Nadeau, P.J., Landry, J., Protein quantification by chemiluminescent Western blotting: elimination of the antibody factor by dilution series and calibration curve. J. Immunol. Methods 2010, 353, 148-50.

[33] Calvo, A.C., Moreno-Igoa, M., Manzano, R., Ordovás, L., et al., Determination of protein and RNA expression levels of common housekeeping genes in a mouse model of neurodegeneration. Proteomics 2008, 8, 4338-43.

[34] Di Modica, M., Regondi, V., Sandri, M., lorio, M. V, et al., Breast cancer-secreted miR-939 downregulates VE-cadherin and destroys the barrier function of endothelial monolayers n.d.

[35] Chen, L., Dempsey, B.R., Gyenis, L., Menassa, R., et al., Identification of the factors that control synthesis and accumulation of a therapeutic protein, human immune-regulatory interleukin-10, in Arabidopsis thaliana. Plant Biotechnol. J. 2013, 11, 546-554.

[36] Hagiwara, M., Kobayashi, K.-I., Tadokoro, T., Yamamoto, Y., Application of SYPRO Ruby- and Flamingo-stained polyacrylamide gels to Western blot analysis. Anal. Biochem. 2010, 397, 262-4.

[37] Moritz, C.P., Marz, S.X., Reiss, R., Schulenborg, T., Friauf, E., Epicocconone staining: a 
powerful loading control for Western blots. Proteomics 2014, 14, 162-8.

[38] Rivero-Gutiérrez, B., Anzola, A., Martínez-Augustin, O., de Medina, F.S., Stain-free detection as loading control alternative to Ponceau and housekeeping protein immunodetection in Western blotting. Anal. Biochem. 2014, 467, 1-3.

[39] Lanoix, D., St-Pierre, J., Lacasse, A.A., Viau, M., et al., Stability of reference proteins in human placenta: general protein stains are the benchmark. Placenta 2012, 33, 151-6.

[40] Rae, T., Bonn, R., Lang, E., Stamenova, S., et al., Utility of a direct dual-mode development analysis on blotted protein mixtures. Anal. Biochem. 2011, 415, 116-25.

[41] Klein, D., Kern, R.M., Sokol, R.Z., A method for quantification and correction of proteins after transfer to immobilization membranes. Biochem. Mol. Biol. Int. 1995, 36, 59-66.

[42] Colella, A.D., Chegenii, N., Tea, M.N., Gibbins, I.L., et al., Comparison of Stain-Free gels with traditional immunoblot loading control methodology. Anal. Biochem. 2012, 430, 108110.

[43] Miller, I., Crawford, J., Gianazza, E., Protein stains for proteomic applications:Which, when, why? Proteomics 2006, 6, 5385-5408.

[44] Svensson, E., Hedberg, J.J., Malmport, E., Bjellqvist, B., Fluorescent in-gel protein detection by regulating the $\mathrm{pH}$ during staining. Anal. Biochem. 2006, 355, 304-6.

[45] Berggren, K., Chernokalskaya, E., Steinberg, T.H., Kemper, C., et al., Background-free, high sensitivity staining of proteins in one- and two-dimensional sodium dodecyl sulfatepolyacrylamide gels using a luminescent ruthenium complex. Electrophoresis 2000, 21, 2509-21.

[46] Berggren, K., Steinberg, T.H., Lauber, W.M., Carroll, J.A., et al., A luminescent ruthenium complex for ultrasensitive detection of proteins immobilized on membrane supports. Anal. Biochem. 1999, 276, 129-43.

[47] Steinberg, T.H., Top, K.P.O., Berggren, K.N., Kemper, C., et al., Rapid and simple single nanogram detection of glycoproteins in polyacrylamide gels and on electroblots. 
Proteomics 2001, 1, 841-855.

[48] Mackintosh, J.A., Choi, H.-Y., Bae, S.-H., Veal, D.A., et al., A fluorescent natural product for ultra sensitive detection of proteins in one-dimensional and two-dimensional gel electrophoresis. Proteomics 2003, 3, 2273-2288.

[49] Bell, P.J.L., Karuso, P., Epicocconone, a novel fluorescent compound from the fungus epicoccumnigrum. J. Am. Chem. Soc. 2003, 125, 9304-5.

[50] Harlow, E., Lane, D., Staining immunoblots for total protein using ponceau s. CSH Protoc. 2006, 2006, pdb.prot4269.

[51] Goldman, A., Harper, S., Speicher, D.W., in:, Curr. Protoc. Protein Sci., vol. 86, John Wiley \& Sons, Inc., Hoboken, NJ, USA 2016, p. 10.8.1-10.8.11.

[52] Romero-Calvo, I., Ocón, B., Martínez-Moya, P., Suárez, M.D., et al., Reversible Ponceau staining as a loading control alternative to actin in Western blots. Anal. Biochem. 2010, 401, 318-20.

[53] Gilda, J.E., Gomes, A. V, Stain-Free total protein staining is a superior loading control to $\beta$-actin for Western blots. Anal. Biochem. 2013, 440, 186-8.

[54] Ladner, C.L., Yang, J., Turner, R.J., Edwards, R.A., Visible fluorescent detection of proteins in polyacrylamide gels without staining. Anal. Biochem. 2004, 326, 13-20.

[55] Gürtler, A., Kunz, N., Gomolka, M., Hornhardt, S., et al., Stain-Free technology as a normalization tool in Western blot analysis. Anal. Biochem. 2013, 433, 105-11.

[56] Ball, M.S., Karuso, P., Mass spectral compatibility of four proteomics stains. J. Proteome Res. 2007, 6, 4313-20.

[57] Peixoto, P.A., Boulangé, A., Ball, M., Naudin, B., et al., Design and synthesis of epicocconone analogues with improved fluorescence properties. J. Am. Chem. Soc. $2014,136,15248-56$.

[58] Moritz, C.P., Eckstein, E., Tenzer, S., Friauf, E., Neuroproteomics in the auditory brainstem: Candidate proteins for ultrafast and precise information processing. Mol. Cell. 
Neurosci. 2015, 64, 9-23.

[59] Congdon, R.W., Muth, G.W., Splittgerber, A.G., The binding interaction of Coomassie blue with proteins. Anal. Biochem. 1993, 213, 407-13.

[60] Smejkal, G.B., Separation methods in proteomics, CRC Taylor \& Francis, 2006.

[61] Pryor, J.L., Xu, W., Hamilton, D.W., Immunodetection after complete destaining of coomassie blue-stained proteins on immobilon-PVDF. Anal. Biochem. 1992, 202, 100-4.

[62] Christiansen, J., Houen, G., Comparison of different staining methods for polyvinylidene difluoride membranes. Electrophoresis 1992, 13, 179-83.

[63] Houen, G., Bruun, L., Barkholt, V., Combined immunostaining and Coomassie Brilliant Blue staining of polyvinylidene difluoride membranes without organic solvent. Electrophoresis 1997, 18, 701-5.

[64] Luo, S., Wehr, N.B., Levine, R.L., Quantitation of protein on gels and blots by infrared fluorescence of Coomassie blue and Fast Green. Anal. Biochem. 2006, 350, 233-8.

[65] Butt, R.H., Coorssen, J.R., Coomassie blue as a near-infrared fluorescent stain: a systematic comparison with Sypro Ruby for in-gel protein detection. Mol. Cell. Proteomics 2013, 12, 3834-50.

[66] Racusen, D., Stoichiometry of the amido black reaction with proteins. Anal. Biochem. 1973, 52, 96-101.

[67] Gentile, F., Balì, E., Pignalosa, G., Sensitivity and applications of the nondenaturing staining of proteins on polyvinylidene difluoride membranes with Amido black 10B in water followed by destaining in water. Anal. Biochem. 1997, 245, 260-2.

[68] Weldon, S., Ambroz, K., Schutz-Geschwender, A., Olive, D.M., Near-infrared fluorescence detection permits accurate imaging of loading controls for Western blot analysis. Anal. Biochem. 2008, 375, 156-8.

[69] Gerk, P.M., Quantitative immunofluorescent blotting of the multidrug resistanceassociated protein 2 (MRP2). J. Pharmacol. Toxicol. Methods 2011, 63, 279-82. 
[70] Chiang, E.T., Lim, M.J., Patton, W.F., Shepro, D., NFkappaB translocation in human microvessel endothelial cells using a four-compartment subcellular protein redistribution assay. J. Biochem. Biophys. Methods 2000, 46, 53-68.

[71] Kurien, B.T., Scofield, R.H., in:, Methods Mol. Biol., vol. 1314, 2015, pp. 357-370.

[72] Zhang, Y., Yu, D., Dai, J., Wang, X., et al., A method for rapid and sensitive negative staining of proteins in SDS-PAGE using 2', 7'-Dichlorofluorescein. Proteomics 2017, 1600346.

[73] Zhou, A., Zhou, T., Yu, D., Shen, Y., et al., Pre-staining of glycoprotein in SDS-PAGE by the synthesis of a new hydrazide derivative. Proteomics 2015, 15, 3623-3628.

[74] Faden, F., Eschen-Lippold, L., Dissmeyer, N., in:, Methods Mol. Biol., vol. 1450, 2016, pp. 247-258.

[75] Fosang, A.J., Colbran, R.J., Transparency Is the Key to Quality. J. Biol. Chem. 2015, 290, $29692-4$.

[76] Hong, H.-Y., Yoo, G.-S., Choi, J.-K., Direct Blue 71 staining of proteins bound to blotting membranes. Electrophoresis 2000, 21, 841-845.

[77] Susnea, I., Bernevic, B., Wicke, M., Ma, L., et al., Application of MALDI-TOF-mass spectrometry to proteome analysis using stain-free gel electrophoresis. Top. Curr. Chem. 2013, 331, 37-54.

[78] Bloemendal, H., Satijn, M., Simple reversible staining of proteins transferred from polyacrylamide gels onto nitrocellulose membranes. Anal. Chim. Acta 1995, 300, 1-3.

[79] Harper, S., Speicher, D.W., Harper, S., Speicher, D.W., in:, Curr. Protoc. Protein Sci., John Wiley \& Sons, Inc., Hoboken, NJ, USA 1995, p. 10.8.1-10.8.7.

[80] Steinberg, T.H., Jones, L.J., Haugland, R.P., Singer, V.L., SYPRO orange and SYPRO red protein gel stains: one-step fluorescent staining of denaturing gels for detection of nanogram levels of protein. Anal. Biochem. 1996, 239, 223-37.

[81] Steinberg, T.H., Haugland, R.P., Singer, V.L., Applications of SYPRO orange and SYPRO 
red protein gel stains. Anal. Biochem. 1996, 239, 238-45.

[82] Patton, W.F., Lam, L., Su, Q., Lui, M., et al., Metal chelates as reversible stains for detection of electroblotted proteins: application to protein microsequencing and immunoblotting. Anal. Biochem. 1994, 220, 324-35.

[83] Shojaee, N., Patton, W.F., Lim, M.J., Shepro, D., Pyrogallol red-molybdate: A reversible, metal chelate stain for detection of proteins immobilized on membrane supports. Electrophoresis 1996, 17, 687-693.

[84] Antharavally, B.S., Carter, B., Bell, P.A., Krishna Mallia, A., A high-affinity reversible protein stain for Western blots. Anal. Biochem. 2004, 329, 276-80. 
Table 1: Properties of proved and tested TPS loading controls

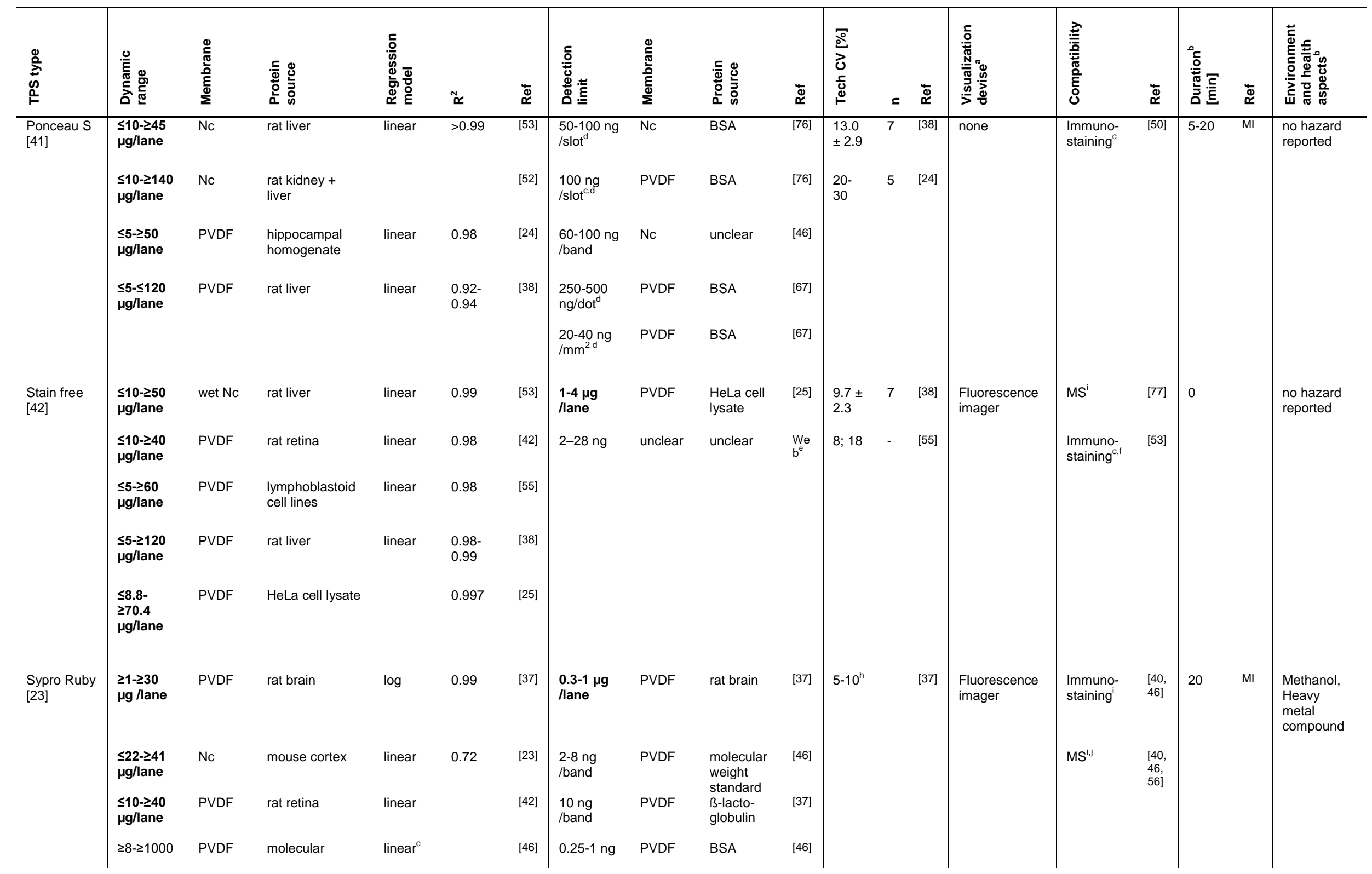




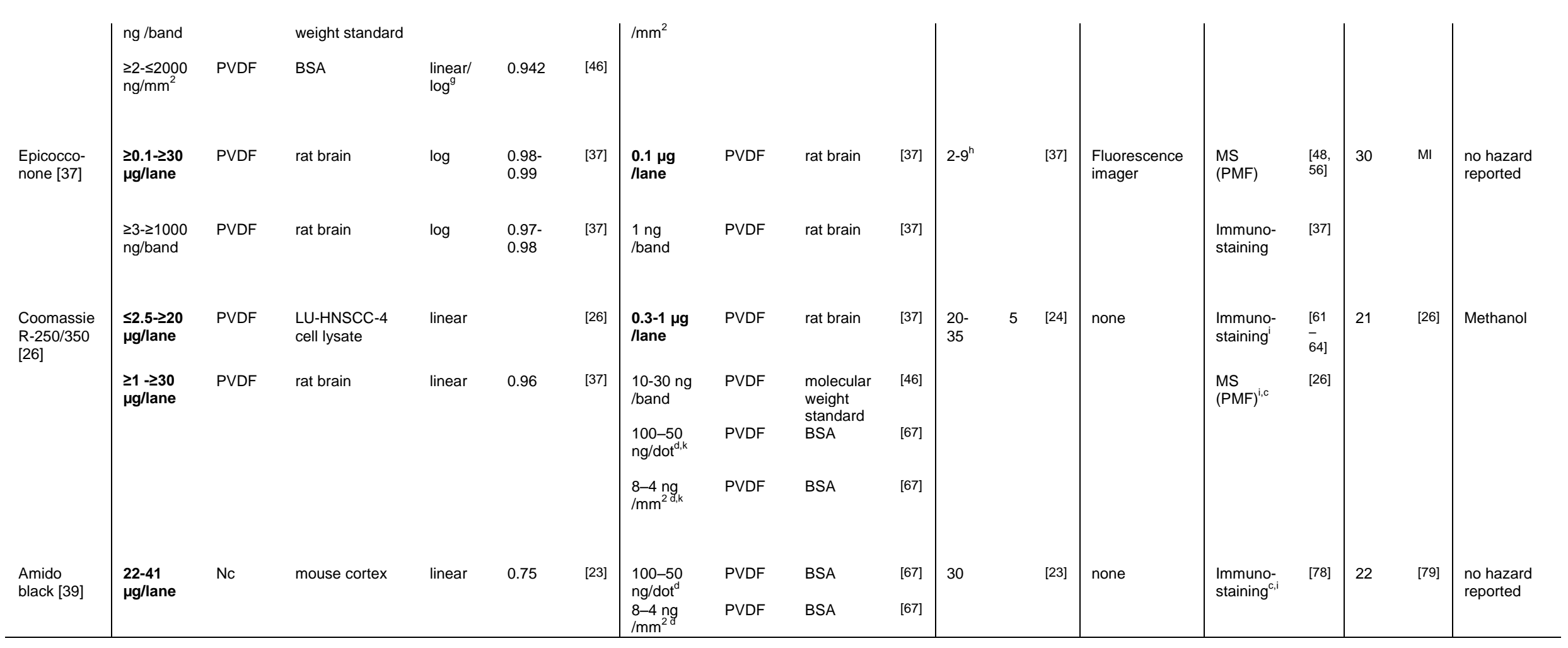

\section{a) apart from common scanner}

b) of staining process including destaining when appropriate

c) no data proof delivered

d) direct dot blotting; no loss by transfer

e) http://www.bio-rad.com/evportal/en/US/LSR/Solutions/LUSQ3K15/Total-Protein-Detection\#4

f) tested for 10 proteins; so far no systematic test addressing antibodies raised toward a peptide region that contains

g) linear according to authors, although raw data look rather logarithmic

h) when loading 3-10 $\mu \mathrm{g}$ total protein per lane; higher when loading $<3 \mu \mathrm{g}$

i) not systematically tested 
j) can inhibit identification of cysteine and tryptophan containing peptides in peptide mass fingerprinting [48]

k) both methanol- and water-based (de)staining

n: sample size

MI: manufacturer instructions

Nc: Nitrocellulose

Protein amounts per lane are shown in bold letters 
Table 2: Properties of further possible TPS loading controls

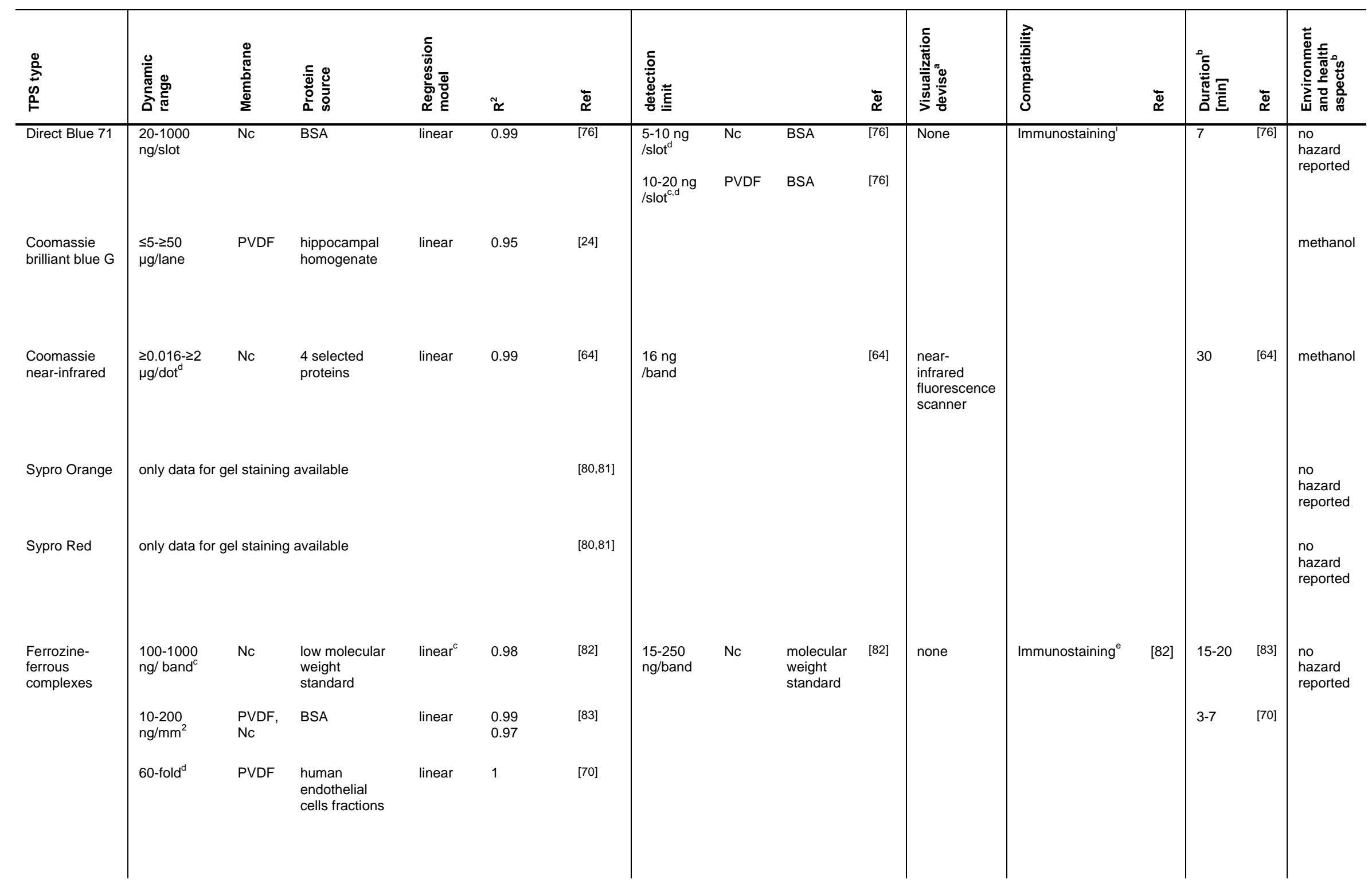




\begin{tabular}{|c|c|c|c|c|c|c|c|c|c|c|c|c|c|c|c|}
\hline $\begin{array}{l}\text { Pyrogallol red- } \\
\text { molybdate } \\
\text { complexes }\end{array}$ & $\begin{array}{l}10-200 \\
\mathrm{ng} / \mathrm{mm}^{2}\end{array}$ & $\begin{array}{l}\text { PVDF, } \\
\text { Nc }\end{array}$ & BSA & linear & $\begin{array}{l}0.97 \\
0.99\end{array}$ & [83] & & & & none & Immunostaining $^{\dagger}$ & [83] & $15-20$ & [83] & $\begin{array}{l}\text { no } \\
\text { hazard } \\
\text { reported }\end{array}$ \\
\hline MemCode $^{T M}$ & $\begin{array}{l}25-500 \\
\mathrm{ng} / \mathrm{band}\end{array}$ & $\mathrm{Nc}$ & $\begin{array}{l}\text { carbonic } \\
\text { anhydrase }\end{array}$ & - & - & [84] & $\begin{array}{l}10 x> \\
\text { Ponceau } \\
S\end{array}$ & $\begin{array}{l}\text { PVDF, } \\
\text { Nc }\end{array}$ & $\begin{array}{l}\text { Molecular } \\
\text { weight } \\
\text { marker }\end{array}$ & none & Immunostaining $^{\dagger}$ & [84] & $10-15$ & [84] & $\begin{array}{l}\text { no } \\
\text { hazard } \\
\text { reported }\end{array}$ \\
\hline
\end{tabular}

\section{a) apart from common scanner}

b) including destaining when appropriate

c) no data proof delivered

d) direct protein plotting; no loss by transfer

e) only shown for related ferrocyanide/ferric complex

f) not systematically tested

Nc: Nitrocellulose 
Figure 1: Application of Western blots as measured by publication numbers. A: Absolute numbers of publications mentioning "Western blot" in the Text Words (cf. main text for details). B: Absolute numbers of publications mentioning "Protein" in the Text Words. C: Percentage of protein-related publications mentioning "Western blot" in the Text Words relative to all proteinrelated publications (cf. main text). D: Percentage of protein-related publications mentioning "Mass spectrometry" in the Text Words relative to all protein-related publications.
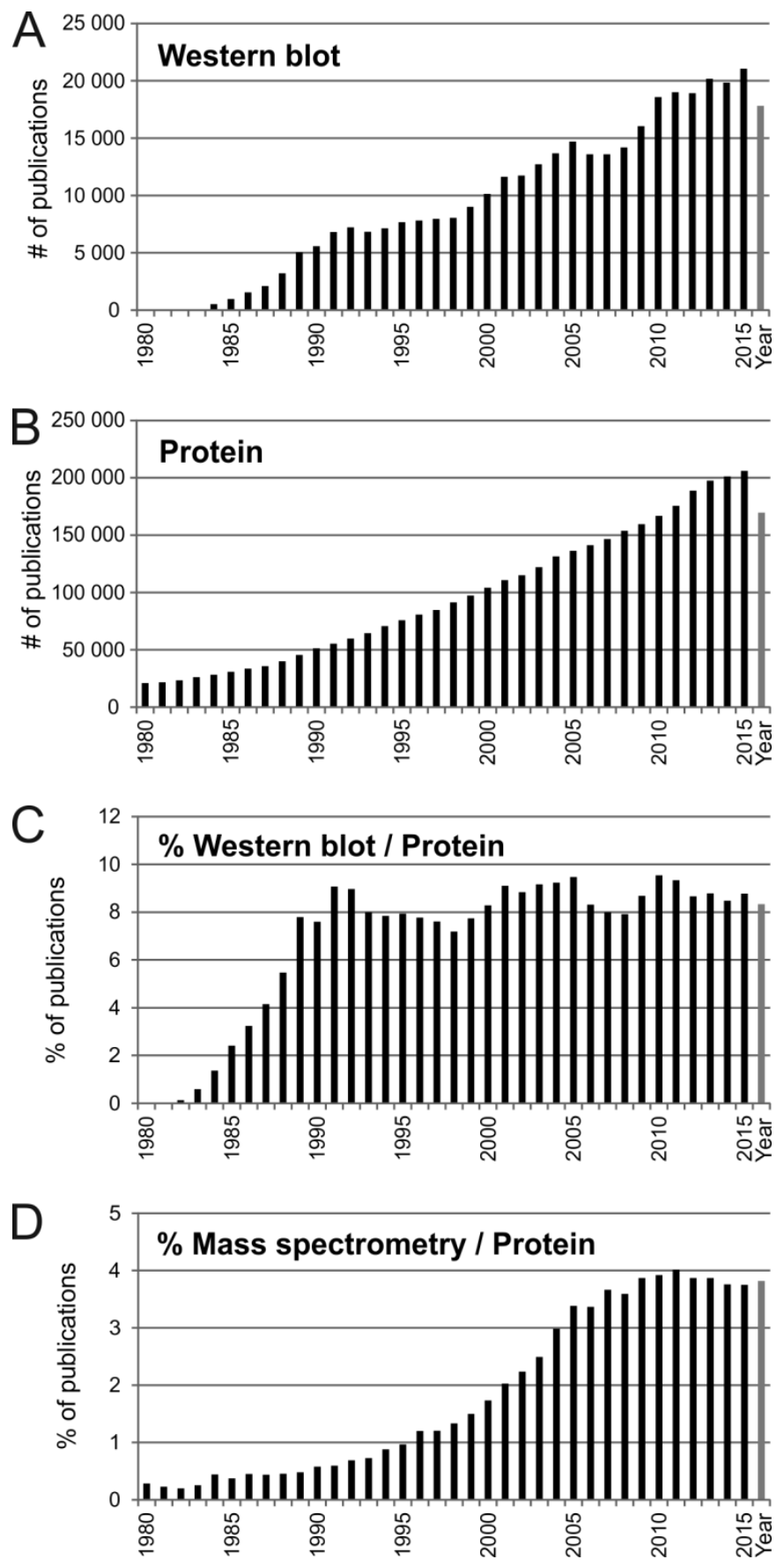
Figure 2: Dynamic ranges of the six proposed TPSs. Lengths of horizontal lines visualize the dynamic ranges of the TPSs. Each line corresponds to one literature reference. Only references with " $\mu \mathrm{g} / \mathrm{lane}$ " values were used for visualization. Arrowheads indicate that the dynamic range may be broader, as the tested total protein amounts have not reached the limits. Grey lines represent rather logarithmic than linear dynamic ranges. Numbers in brackets indicate literature references.

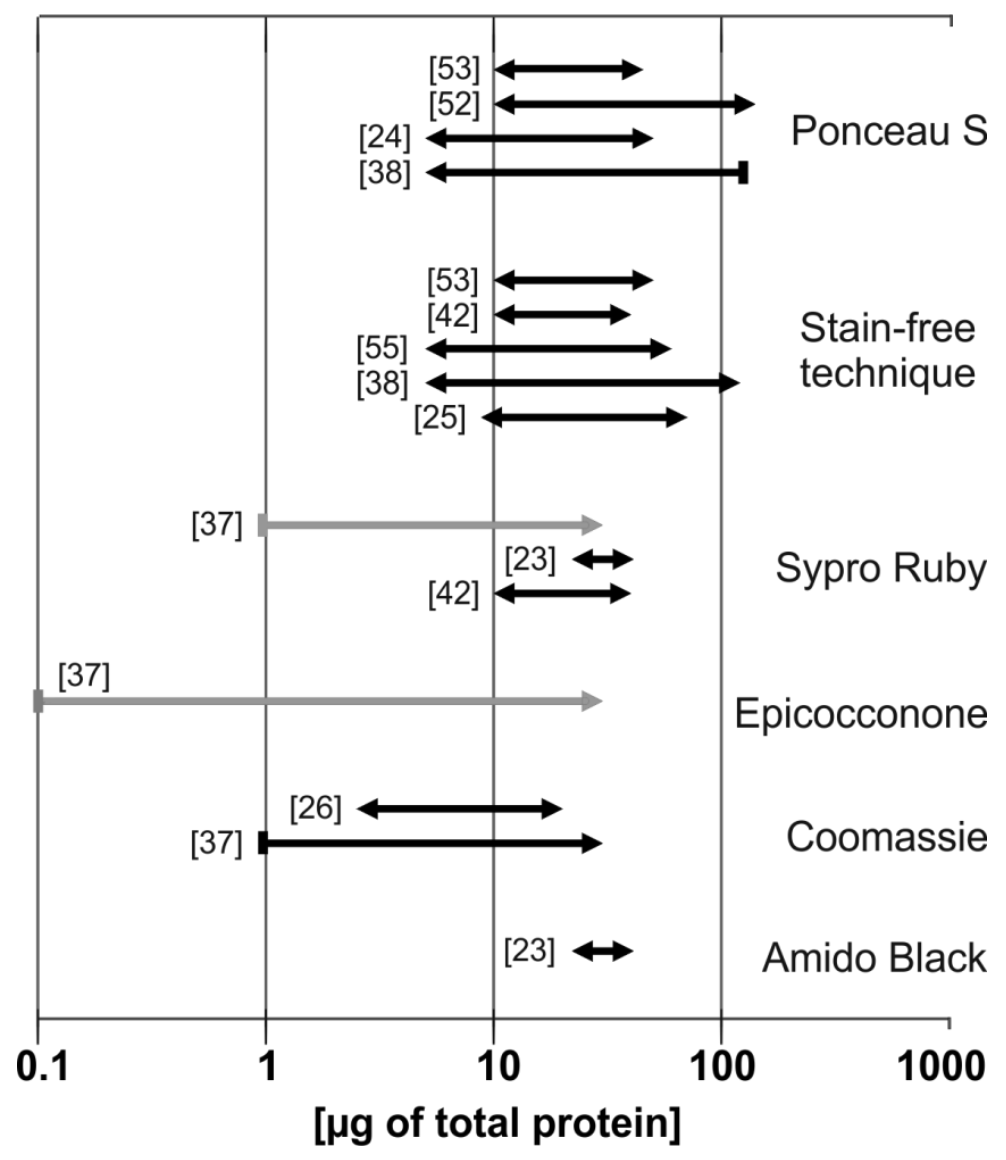




\section{Supplementary Table 1}

\begin{tabular}{|c|c|c|c|c|c|c|c|}
\hline Staining type & $\begin{array}{l}\text { Product } \\
\text { reference }\end{array}$ & Distributor & Prize/unit $[€]$ & $\begin{array}{l}\text { Amount } \\
{[\mathrm{mL}]}\end{array}$ & $\begin{array}{l}\text { needed } \\
\text { amount } \\
\text { /exp }[\mathrm{mL}]\end{array}$ & $\begin{array}{l}\text { sufficient } \\
\text { for \#gels }\end{array}$ & Prize/gel \\
\hline Ponceau & P7170-1L & Sigma Aldrich & 116.2 & 1000 & 5 & 200 & 0.58 \\
\hline Stain free & 1610181 & BioRad & 232 & & & $65^{\mathrm{a}}$ & $2.77^{\mathrm{b}}$ \\
\hline Sypro Ruby & S4942-1L & Sigma Aldrich & 442.5 & 1000 & 5 & 200 & 2.21 \\
\hline Epicocconone & 43386.02 & $\begin{array}{l}\text { SERVA } \\
\text { Electrophoresis }\end{array}$ & 995 & 100 & 0.25 & 400 & 2.49 \\
\hline $\begin{array}{l}\text { Coomassie R- } \\
\text { 250/350 }\end{array}$ & B6529-1L & Sigma Aldrich & 199.2 & 1000 & 5 & 200 & 1.00 \\
\hline Amido black & A8181-1EA & Sigma Aldrich & 137 & 500 & 5 & 100 & 1.37 \\
\hline $\begin{array}{l}\text { Anti-Tubulin } \\
\text { antibody }\end{array}$ & T3526-1ML & Sigma Aldrich & 882 & 1 & 0.025 & 40 & 22.05 \\
\hline $\begin{array}{l}\text { Anti-Actin } \\
\text { antibody }\end{array}$ & A2066-.2ML & Sigma Aldrich & 390.5 & 0.2 & 0.05 & 4 & 97.63 \\
\hline $\begin{array}{l}\text { HRP-coupled sec. } \\
\text { Ab }\end{array}$ & A0545-1ML & Sigma Aldrich & 244 & 1 & 0.003 & 333.3333333 & 0.73 \\
\hline
\end{tabular}

a) indicated at BioRad homepage; full kit; $1 \mathrm{~mm}$ spacer

b) this prize is the difference between the 1 liter bottle of acrylamide (standard) and the stain-free variant (only available as ready to use $7.5 \%$ ) 